\title{
Chitin-glucan complex - Based biopolymeric structures using biocompatible ionic liquids
}

Inês C. Ferreira ${ }^{\mathrm{a}, \mathrm{b}}$, Diana Araújo ${ }^{\mathrm{b}}$, Pierre Voisin ${ }^{\mathrm{a}}$, Vítor D. Alves ${ }^{\mathrm{c}}$, Andreia A. Rosatella ${ }^{\mathrm{d}}$, Carlos A.M. Afonso ${ }^{\mathrm{d}}$, Filomena Freitas ${ }^{\mathrm{b}}$, Luísa A. Neves ${ }^{\mathrm{a}, *}$

${ }^{a}$ LAQV-REQUIMTE, Chemistry Department, Faculdade de Ciências e Tecnologia, Universidade Nova de Lisboa, 2829-516 Caparica, Portugal b UCIBIO-REQUIMTE, Chemistry Department, Faculdade de Ciencias e Tecnologia, Universidade Nova de Lisboa, 2829-516 Caparica, Portugal

${ }^{\mathrm{C}}$ LEAF, Linking Landscape, Environment, Agriculture and Food, Instituto Superior de Agronomia, Universidade de Lisboa, Tapada da Ajuda, 1349-017 Lisboa, Portugal

${ }^{a}$ Instituto de Investigaçāo do Medicamento (iMed.ULisboa), Faculty of Pharmacy, Universidade de Lisboa, Av. Prof. Gama Pinto, 1649-003 Lisboa, Portugal

\section{A R T I C L E I N F O}

Keywords:

Chitin-glucan complex (CGC)

Biopolymers

Ionic liquids (ILs)

Films

Gels

\begin{abstract}
A B S T R A C T
This work explores the novelty of dissolving chitin-glucan complex (CGC), from two fungal strains, Komagataella pastoris ( $\mathrm{CGC}_{\mathrm{p}}$ ) and Aspergillus niger ( $\mathrm{CGC}_{\mathrm{KZ}}$ ) (KiOnutrime-CG ${ }^{\mathrm{m}}$ ), using biocompatible ionic liquids (ILs). Three cholinium-based ILs were tested, choline acetate, choline propionate and choline hexanoate. Although all tested ILs resulted in the dissolution of the co-polymer at a concentration of $5 \%(w / w)$, distinct polymeric structures, films or gels, were obtained from $\mathrm{CGC}_{\mathrm{p}}$ and $\mathrm{CGC}_{\mathrm{KZ}}$, respectively. $\mathrm{CGC}_{\mathrm{p}}$ films were dense, flexible and elastic, with high swelling capacity ( $>200 \%$ ). The IL anion alkyl chain length influenced the polymeric structures' properties, namely, the $\mathrm{CGC}_{\mathrm{p}}$ films elongation at break and swelling degree. $\mathrm{CGC}_{\mathrm{KZ}}$ resulted in weak gels. For both polymeric structures, exposure to the IIs under the dissolution conditions caused significant changes in the copolymers' chemical structure, namely, reduction of their glucan moiety and reduction of the degree of acetylation, thus yielding chitosan-glucan complexes (ChGC) enriched in glucosamine (53.4 $\pm 0.3-60.8 \pm 0.3 \%$ ).
\end{abstract}

\section{Introduction}

Chitin-glucan complex (CGC) is a polysaccharide found in the cell wall of most fungi and yeasts, including, for example, Komagataella pastoris (Farinha et al., 2015; Farinha, Freitas, \& Reis, 2017), Aspergillus niger (Feofilova, Nemtsev, Tereshina, \& Memorskaya, 2006; Skorik, Pestov, \& Yatluk, 2010), Schizophyllum commune (Abdel-mohsen, Jancar, Massoud, Fohlerova, \& Elhadidy, 2016), Gongronella butleri (Nwe, Stevens, Tokura, \& Tamura, 2008), Armillariella mellea (Ivshin, Artamonova, Ivshina, \& Sharnina, 2008) and Saccharomyces cerevisie (Beran, Holan, \& Baldrián, 1972). This natural co-polymer comprises a chitin moiety ( $N$-acetyl-D-glucosamine units), which is covalently linked to a $\beta$-glucans moiety (glucose units). CGC combines the properties of chitin and $\beta$-glucans, both possessing biological activity, being biocompatible and biodegradable, with antioxidant, antibacterial and antiinflammatory properties (Jayakumar et al., 2011; Lehtovaara \& Gu, 2011). All these properties make this biopolymer attractive for a variety of applications, such as its use as a food additive (EFSA Panel on Dietetic Products Nutrition \& Allergies, 2010), a cosmetic ingredient (Gautier, Xhauflaire-Uhoda, Gonry, \& Piérard, 2008), for heavy metal removal (Pestov, Drachuk, Koryakova, \& Yatluk, 2009), wine clarification (Bornet \& Teissedre, 2008) or as wound dressing material (Abdel-mohsen et al., 2016; Araújo, Ferreira, Torres, Neves, \& Freitas, 2019).

Despite its demonstrated suitability for many uses, the full potential of CGC has been hindered mainly by its insolubility in water and most common organic solvents (Araújo, Alves et al., 2019; Farinha et al., 2015). This insolubility is mainly due to the high number of inter and intra-molecular hydrogen bonds between the functional groups of chitin and $\beta$-glucans. Similarly to chitin, CGC is soluble in toxic and/or corrosive polar solvents, such as, $\mathrm{N}, \mathrm{N}$-dimethylacetamide(DMAc)/lithium chloride(LiCl) (Poirier \& Charlet, 2002) system, being the resultant solutions often unstable, which turns their processing very difficult.

In the last decades, ionic liquids (ILs) have been used as alternative solvents for the dissolution of natural biopolymers known for their intractability, such as chitin, cellulose, lignin and starch (Becherini, Mezzetta, Chiappe, \& Guazzelli, 2019; Li et al., 2020; Shamshina \& Berton, 2020; Silva, Mano, \& Reis, 2017; Wu, Wang, Li, Li, \& Wang, 2009; Yang, Qiao, Li, \& Li, 2016). ILs are salts with low melting point, usually below $100^{\circ} \mathrm{C}$. These solvents possess nonflammability, negligible volatility and their chemical and physical properties can be tuned 
by changing the cation or the anion in their structure, making them very attractive for a variety of applications, including as solvents for dissolution of biopolymers (Petkovic, Seddon, Rebelo, \& Pereira, 2011; Silva et al., 2017). Besides ILs, deep eutectic solvents (DESs) were also reported to have good solvent properties for polysaccharides. DESs are mixtures obtained by the combination of two or more components, resulting in a mixture with a lower melting point than each initial components (Chen et al., 2018; González-Rivera et al., 2020; Martins, Pinho, \& Coutinho, 2019). These mixtures share some properties of ILs such as, nonflammability, low volatility and tailorable physicochemical properties which allied to their easy preparation turns them also interesting materials for polysaccharides dissolution (Lynam, Kumar, \& Wong, 2017; Tang et al., 2017; Wang et al., 2020).

Concerning ILs, Swatloski, Spear, Holbrey, and Rogers (2002)) studied the capability of different ILs, constituted by 1-butyl-3-methylimidazolium cation [BMIM] ${ }^{+}$and different anions, to dissolve cellulose, concluding that the anion $[\mathrm{Cl}]^{-}$was the most effective. That work opened new routes for the use of ILs as solvents for natural polysaccharides. ILs such as 1-butyl-3-methylimidazolium acetate ([BMIM]Ac) (Wu, Sasaki, Irie, \& Sakurai, 2008), 1-ethyl-3-methylimidazolium acetate ([EMIM]Ac) (Qin, Lu, Sun, \& Rogers, 2010), 1-allyl-3methylimidazolium chloride ([AMIM]Cl) (Wang, Zhu, Wang, Huang, \& Wang, 2010), 1-allyl-3-methylimidazolium acetate ([AMIM]Ac) (Wang et al., 2010) and 1-allyl-3-methylimidazolium bromide ([AMIM]Br) (Prasad et al., 2009) were found also to dissolve chitin. The dissolving ability of ILs is related to their capacity of disrupting hydrogen bonds, favored by carboxylic acid anions such as acetate (Ac-), that was reported to easily dissolve biopolymers, namely, cellulose and chitin/ chitosan (Yang et al., 2016).

Although several ILs have been reported as potential solvents for biopolymers, in a way to explore biomedical applications, it is important to access their cytotoxicity. According to previous reports, ILs toxicity increases with the increase of the cation alkyl chain length. For shorter alkyl chain lengths the anion has a higher impact in the overall toxicity (Frade \& Afonso, 2010; Stolte et al., 2006; Zhang et al., 2017). Choline, a quaternary ammonium cation, is a natural green product, which is a micronutrient for the function of all cells and its absence in adult animals and humans can lead to several diseases, such as fatty liver. Cholinium-based ILs have been reported as low toxic, biodegradable and when combined with alkanoate anions, can lead to the formation of highly promising biocompatible ILs for biotechnological applications (Araújo et al., 2014; Gunaratne et al., 2010).

This work explores a novel green strategy, based on the use of biocompatible ILs, for dissolution of CGC and the preparation of valuable polymeric structures with distinct properties suitable for various applications. For that, CGC from two distinct sources, namely, the yeast Komagataella pastoris $\left(\mathrm{CGC}_{\mathrm{p}}\right)$ and the fungus Aspergillus niger $\left(\mathrm{CGC}_{\mathrm{KZ}}\right)$ with different glucosamine contents were tested. Three choliniumbased ILs, were selected for CGC dissolution, choline acetate ([CHOL]Ac), choline propionate ([CHOL]Prop) and choline hexanoate $([\mathrm{CHOL}] \mathrm{Hx})$. For the development of CGC polymeric structures the phase inversion method was applied and CGC polymeric structures in form of films or gels were obtained. Several techniques including, elemental analysis, Fourier Transform Infrared (FTIR) spectroscopy, Scanning Electron Microscopy (SEM), water contact angle, mechanical properties, swelling tests and rheological measurements were employed to characterize chemically and physically the produced biopolymeric structures.

\section{Materials and methods}

\subsection{Ionic liquids selection, synthesis and characterization}

The ILs, eutectic mixtures and PEGs with different molecular weight, used for the preliminary screening solubility experiments were provided by our laboratory collection (Frade et al., 2009; Rosatella,
Branco, \& Afonso, 2009). Choline hydroxide (46 wt.\% in $\mathrm{H}_{2} \mathrm{O}$, SigmaAldrich), acetic acid glacial (Fluka ${ }^{\mathrm{TM}}$, Honeywell, Germany), propionic acid (for synthesis, Merck, Germany) and hexanoic acid (for synthesis, Merck, Germany), were used as received.

Selected ionic liquid synthesis. All selected ILs were synthesized through an acid-base reaction according to the literature (Martins et al., 2016). Each carboxylic acid (acetic acid, propionic acid and hexanoic acid - $1 \mathrm{~mol}$ ) was added dropwise to a solution of choline hydroxide (1 mol). The mixture was left under stirring during $24 \mathrm{~h}$, at room temperature. After that, the resultant IL was dried under vacuum, using a rotary evaporator, followed by vacuum line drying ( $<5 \mathrm{mbar}$ ) for at least $24 \mathrm{~h}$. The ILs' purity was confirmed by ${ }^{1} \mathrm{H}$ NMR analysis ( $>95 \%$ ).

Ionic liquid characterization. [CHOL]Ac, [CHOL]Prop, [CHOL] Hx apparent viscosity and density were determined using a SVM ${ }^{\mathrm{NA}} 3001$ Viscosimeter (Anton Paar $\mathrm{GmbH}$, Austria). The measurements were performed over a temperature range of $30^{\circ} \mathrm{C}$ to $110^{\circ} \mathrm{C}$, based on the CGC dissolution temperature conditions. The water content was also determined, through Karl-Fisher titration method (model $831 \mathrm{KF}$ Coulometer, Methrohm AG, Switzerland). Fourier transform infrared spectroscopy (FTIR) was carried out using a Perkin-Elmer Spectrum $\mathrm{Two}^{\mathrm{TM}}$, with a detector type L1600300 equipped with attenuated total reflectance (ATR) accessory. The spectra were recorded based on five scans performed in the mid-infrared range of $400-4000 \mathrm{~cm}^{-1}$.

Preliminary screening. CGC portions ( $10 \mathrm{mg}$ scale $\mathrm{CGC}_{\mathrm{p}}$ ) were sequentially added to the ILs, deep eutectic mixtures or PEG (1 g scale), at $70{ }^{\circ} \mathrm{C}$, and left under stirring, until complete dissolution was observed.

\subsection{Chitin-glucan complex characterization}

CGC of two distinct origins were used in this study, namely, the copolymers extracted from the cell walls of the yeast $K$. pastoris (CGC $)$ and of the fungus $A$. niger (KiOnutrime- $\mathrm{CG}^{\mathrm{m}}$ ) that is commercialized by KitoZyme $\left(\mathrm{CGC}_{\mathrm{KZ}}\right)$. CGCp was obtained by cultivation of $K$. pastoris DSM 70877, using glycerol as carbon source, as described by Farinha et al. (2015). The co-polymer was extracted from the yeast biomass through hot alkaline procedure as described by Araújo, Freitas, Sevrin, Grandfils and Reis (2017).

\subsubsection{Glucosamine content and degree of acetylation}

The C, N and $\mathrm{H}$ contents in each CGC sample were obtained through elemental analysis using a Flash EA 1112 Series CHNS analyser. The glucosamine content (GlcN, \%) was calculated using the following equation (US Pat., 20160122444A1, 2016),

GlcN $=14.199 \times N$

where $\mathrm{N}$ is the nitrogen content (\%) in the sample.

The acetylation degree (DA) was obtained using the following equation (Xu, McCarthy, Gross, \& Kaplan, 1996),

$D A=\left(\frac{C / N-5.14}{1.72}\right) \times 100 \%$

where $\mathrm{C}$ and $\mathrm{N}$ are the carbon and nitrogen contents (\%), respectively, in the CGC sample.

\subsubsection{Fourier transform infrared spectroscopy}

Fourier transform infrared spectroscopy (FTIR) was carried out using a Perkin-Elmer Spectrum Two ${ }^{\mathrm{TM}}$, with a detector type L1600300 equipped with ATR accessory. Dried CGC samples $(\sim 2 \mathrm{mg})$ were used. The spectra were recorded based on five scans performed in the midinfrared range of $400-4000 \mathrm{~cm}^{-1}$.

\subsection{Polymeric structures preparation}

For the preparation of the polymeric structures, CGC samples $(0.75 \mathrm{~g})$ were mixed with the different ILs $(15 \mathrm{~g})$ to yield $5 \mathrm{wt} \% \mathrm{mix}$ tures. The mixtures were heated in a silicone oil bath (Baysilone ${ }^{\odot}$ 
M350), under continuous stirring (200 rpm), for $24 \mathrm{~h}$, using a heating magnetic stirrer (AREX Heating Magnetic Stirrer, Velp Scientifica ${ }^{\circ}$, Italy). The bath temperature was controlled using a thermo-regulator connected to the heating magnetic stirrer. For an efficient dissolution of the polymer, and based on previous studies (Ardiyanti, 2014; de Oliveira, 2016), a temperature of $110^{\circ} \mathrm{C}$ and $80^{\circ} \mathrm{C}$ was set for $\mathrm{CGC}_{\mathrm{KZ}}$ and CGCp, respectively. Afterwards, the mixture was casted into a metal plate $(6.5 \mathrm{~cm}$ of diameter), and immersed in a coagulation bath at room temperature, for $24 \mathrm{~h}$, for the removal of the IL. This phase-inversion method was applied using water as non-solvent, since all the tested ILs are water-soluble, while the polymer is insoluble. After the coagulation bath, the coagulated polymer was left to dry, at room temperature, for 2-3 days.

\subsection{Polymeric structures characterization}

Both films and gels were characterized through FTIR and their glucosamine content and degree of acetylation determined, using the same procedures as for the CGC dried polymer. In addition, to quantify the amount of the ionic liquid remaining in the polymeric structures an extraction procedure was carried out.

Films' IL extraction procedure. $1 \mathrm{~g}$ of $\mathrm{CGC}_{\mathrm{p}}$ film was treated with $20 \mathrm{~mL}$ of methanol and stirred for $72 \mathrm{~h}$. After that, the methanol-soluble fraction was filtered in cotton and the methanol was evaporated. The resulting mixture was treated with acetone, stirred for $24 \mathrm{~h}$ and filtered once more. The IL was isolated by acetone evaporation.

Gels' IL extraction procedure. $1 \mathrm{~g}$ of $\mathrm{CGC}_{\mathrm{KZ}}$ gel was treated with $20 \mathrm{~mL}$ of methanol and stirred for $2 \mathrm{~h}$. After that, the methanol-soluble fraction was filtered in cotton and the methanol was evaporated. The resulting solution was treated with acetone, stirred for $24 \mathrm{~h}$ and filtered once more. The IL was isolated by acetone evaporation.

The nitrogen and carbon contents due to the ILs contents were taken into account in the calculations of both GlcN and DA of the polymeric structures.

\subsection{Films characterization}

\subsubsection{Scanning Electron microscopy}

Scanning electron microscopy images (SEM) of the surface and cross-section of the films were performed using a JSM7001F JEOL FEGSEM with an electron beam intensity of $10-\mathrm{kV}$. All samples were covered with a layer of Au-Pd to induce charge under the electron beam.

\subsubsection{Contact angle measurements}

Contact angle measurements were made in order to evaluate the hydrophilicity of the produced films using a software of KSV (CAM2008). In this analysis, a drop of deionized water was placed at the film surface (sessile drop method). Three replicates for each sample were taken and an averaged final value of the contact angle was obtained. The film was considered hydrophilic if the angle between the water drop and the film surface was inferior to $90^{\circ}$, and hydrophobic if the angle was superior to $90^{\circ}$.

\subsubsection{Puncture tests}

The films mechanical resistance and elongation were determined through the performance of puncture tests, using a TA-XT Plus Texture analyser (Stable Micro Systems, UK). A $2 \mathrm{~mm}$ diameter cylindrical probe was used to puncture the samples at a velocity of $1 \mathrm{~mm} / \mathrm{s}$, which were immobilized on a flat platform with a $10 \mathrm{~mm}$ diameter hole. The measurements were performed at room temperature using samples with $3 \times 3 \mathrm{~cm}$. Three replicates were done for each sample and the average values of puncture strength and elongation are reported.

\subsubsection{Swelling tests}

The capacity to absorb water was measured through the performance of swelling tests. The CGC films were cut in pieces with $1 \times 1 \mathrm{~cm}$ and their weight was measured. The samples were then immersed in deionized water, for $24 \mathrm{~h}$, at $30^{\circ} \mathrm{C}$. Afterwards, the samples were withdrawn, and their weight measured again. The swelling of the films was measured through the following equation,

Swelling $(\%)=\frac{m_{\text {wet }}-m_{i}}{m_{i}} \times 100 \%$

Where $\mathrm{m}_{\text {wet }}$ is the mass $(\mathrm{g})$ of the wet film and $\mathrm{m}_{1}$ is the mass $(\mathrm{g})$ of the dry film.

\subsection{Gels characterization}

CGC gels were placed in conditioned environments with four different saturated salt solutions in order to evaluate the impact of different relative humidity $(\mathrm{RH})$ levels on the final properties of the structures. This procedure was carried out at $30^{\circ} \mathrm{C}$, during two weeks. Potassium acetate $\left(\mathrm{CH}_{3} \mathrm{COOK}-\mathrm{RH}: 21.6 \%\right)$ (Fischer Scientific, UK), sodium bromide ( $\mathrm{NaBr}$ - RH: $56.0 \%$ ) (PanReac Applichem, Germany), sodium chloride ( $\mathrm{NaCl}-\mathrm{RH}: 75.1 \%$ ), (Fluka ${ }^{\mathrm{m}}$, Honeywell, Germany) and potassium chloride ( $\mathrm{KCl}-\mathrm{RH}: 83.6 \%$ ), (Fluka ${ }^{\mathrm{T \mu}}$, Honeywell, Germany) were used (Greenspan, 1977).

\subsubsection{Rheological properties}

Rheology tests were performed to measure the viscoelastic properties of the CGC gels, stabilized at the different relative humidity values. These tests were performed using a rheometer Haake Mars ${ }^{\text {TI }}$ III (Thermo Scientific, Germany) with a corrugated plate-plate geometry with $2 \mathrm{~cm}$ of diameter. Stress sweeps were carried out to evaluate the linear viscoelastic region, at constant frequency of $1 \mathrm{~Hz}$, and temperature of $25^{\circ} \mathrm{C}$, for the range of shear stress from $0.001-1000 \mathrm{~Pa}$. Afterwards, frequency sweeps were performed at constant tension, within the linear viscoelastic region. In each measurement, the elastic ( $\left.G^{\prime}\right)$ and viscous $(G$ ") moduli as a function of the frequency $(f)$ were determined.

\section{Results and discussion}

\subsection{CGC characterization}

\subsubsection{Glucosamine content and degree of acetylation}

CGC $_{\mathrm{KZ}}$ presented a glucosamine (GlcN) content of $50.5 \pm 0.2 \%$, which is within the values reported for KiOnutrime- $\mathrm{CG}^{\mathrm{TM}}(30-60 \%)$ (EFSA Panel on Dietetic Products Nutrition \& Allergies, 2010). CGC had a GlcN content of $28.0 \pm 0.1 \%$ as determined by Eq. 1 based on elemental analysis. This value is identical to that determined by HPLC after polymer acid hydrolysis (Farinha et al., 2015), which thus validates the use of elemental analysis for glucosamine quantification. This method has the advantage of also allowing the determination of the DA, based on the use of Eq. 2. CGC $\mathrm{Kz}$ and $\mathrm{CGC}_{\mathrm{p}}$ had degree of acetylation (DA) values of $74.2 \pm 0.7 \%$ and $69.9 \pm 0.6 \%$, respectively. CGC had an average molecular weight $(\mathrm{Mw})$ of $4.9 \times 10^{5} \mathrm{Da}$ and a total protein content of $3.0 \pm 0.04 \mathrm{wt} . \%$ (Farinha et al., 2015), while KiOnutrime- $\mathrm{CG}^{\mathrm{m}}$ had a protein content below $6 \mathrm{wt} . \%$ (the $\mathrm{Mw}$ is not available) (EFSA Panel on Dietetic Products Nutrition \& Allergies, 2010).

\subsubsection{Fourier Transform-Infrared Analysis (FTIR)}

The FTIR spectra of $\mathrm{CGC}_{\mathrm{KZ}}$ and $\mathrm{CGC}_{\mathrm{p}}$ (Fig. 1) are similar to those described in previous works (Farinha et al., 2015). Both samples show a broad band near $3300 \mathrm{~cm}^{-1}$, corresponding to the $\mathrm{O}-\mathrm{H}$ stretching of the hydroxyl groups, which is common to all polysaccharides (Cárdenas, Cabrera, Taboada, \& Miranda, 2004; Lu et al., 2013; Wang et al., 2010). The peaks around $2920 \mathrm{~cm}^{-1}$ and $2860 \mathrm{~cm}^{-1}$, assigned to $\mathrm{C}-\mathrm{H}$ stretching of $\mathrm{CH}_{2}$ and $\mathrm{CH}_{3}$ groups are also observed, especially in the CGC $_{\text {p }}$ polymer spectrum (Farinha et al., 2015; Synytsya \& Novak, 2014). Chitin presence in the polymer structure can be observed through the appearance of peaks within the region of 1660 to 


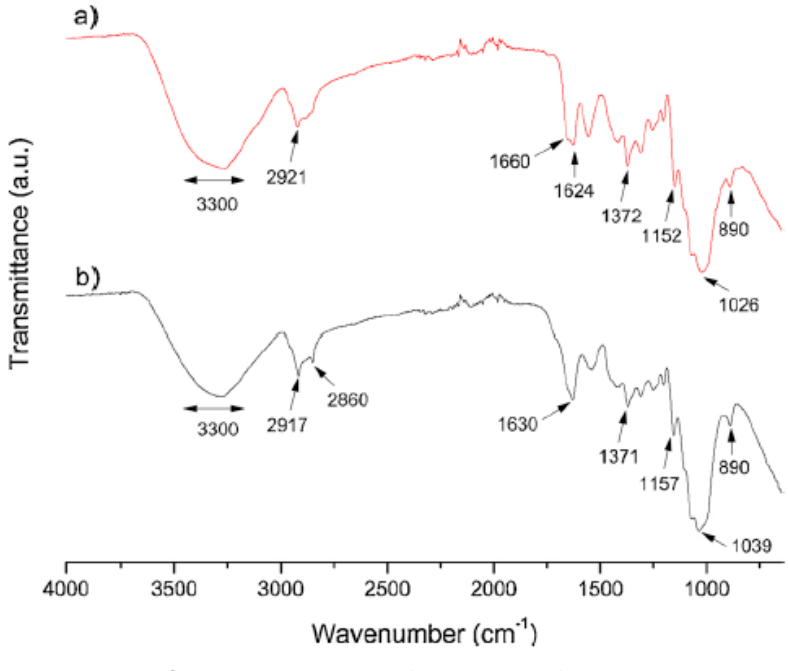

Fig. 1. FTIR spectra of a) $\mathrm{CGC}_{\mathrm{KZ}}$ and b) $\mathrm{CGC}_{\mathrm{p}}$.

$1620 \mathrm{~cm}^{-1}$ corresponding to $\mathrm{C}=\mathrm{O}$ stretching (amide I). In $\mathrm{CGC}_{\mathrm{KZ}}$, two peaks, near $1660 \mathrm{~cm}^{-1}$ and $1623 \mathrm{~cm}^{-1}$, are detected. According to the literature, the existence of two peaks is assigned to a $\alpha$-chitin polymorphism (Jang, Kong, Jeong, Lee, \& Nah, 2004; Kaya, Erdogan, Mol, \& Baran, 2015). In the case of CGCp, as also reported by Farinha et al. (2015), instead of two peaks, a broad band at $1660-1623 \mathrm{~cm}^{-1}$ is observed, which makes difficult the assessment of chitin polymorphism ( $\alpha$-chitin or $\beta$-chitin). The $\beta$-glucan units linkage, can be acknowledged by the presence of small peaks at 890,1156 and $1370 \mathrm{~cm}^{-1}$, which are characteristic of $\beta$-(1,3)-glucans linkage (Corradi da Silva et al., 2008).

\subsection{Ionic liquid selection and characterization}

In order to identify the most efficient solvent system for the dissolution of CGC, a set of screening dissolution experiments was performed. Besides ILs, Deep Eutectic Solvents (DESs) and polyethylene glycol (PEG) have been reported as good solvents for several molecules (Hirano, Shiraki, \& Arakawa, 2012; Zdanowicz, Wilpiszewska, \& Spychaj, 2018). Thus, they were also tested for preliminary studies of dissolution of CGC. A small scale (1 g) of ILs (Fig. 2, 1-10), eutectic mixtures (Fig. 2, 11-16) and PEG were used, by successive addition of $\mathrm{CGC}$, at $70^{\circ} \mathrm{C}$.

In the case of imidazolium cation based ILs 1-4, only for ILs 2 and 3, containing the chloride anion, dissolution of CGC above $5 \%(w / w)$ was observed. Similar dissolution was observed for the guanidinium based ILs (7). In the case of choline based ILs, ILs 5 and 6, a dissolution of up to $4 \%$ was observed, and only for [CHOL]Ac (8), [CHOL]Prop (9) and [CHOL] Hx (10) dissolution values above $5 \%$ were observed.

For all eutectic mixtures tested (11-16), low dissolution was observed $(<4 \%$ ) and for PEG (PEG 400, PEG 300, PEG B21/240 and PEG 600, all liquid at room temperature) no visual dissolution of CGC was observed and instead, a dispersion of CGC in PEG was formed.

Considering their ability for dissolving CGC, together with the benign nature of the choline cation (Gunaratne et al., 2010), choline carboxylates [CHOL]Ac, [CHOL]Prop, [CHOL] Hx (ILs 8, 9 and 10), were selected for the subsequent studies.

The selected ionic liquids were characterized in terms of water content, viscosity and density. The water content was measured at room temperature, with [CHOL]Ac having the highest content (27.6\%), followed by [CHOL]Prop and [CHOL] Hx, with similar values $(11.0 \%$ and $11.4 \%$, respectively). According with previous studies, the ideal dissolution temperatures for CGC were determined to be $80^{\circ} \mathrm{C}$ for CGC $_{\mathrm{p}}$ and $110^{\circ} \mathrm{C}$ for $\mathrm{CGC}_{\mathrm{KZ}}$ (Ardiyanti, 2014; de Oliveira, 2016). In this way, the viscosity and density of the ILs, at $30^{\circ} \mathrm{C}, 80^{\circ} \mathrm{C}$ and $110^{\circ} \mathrm{C}$, were determined (Table 1). It can be observed that the density decreases with the increase of the anion alkyl chain length for all the tested temperatures. This behaviour was already observed for other cholinium and aminoacid-based ILs, being attributed to the increase of free volume as a result of the alkyl chain length increase (Muhammad et al., 2012; Zhang et al., 2009). Additionally, there was a reduction of the ILs density as the temperature was raised from 30 to $110^{\circ} \mathrm{C}$.

[CHOL]Prop and [CHOL]Hx showed similar apparent viscosity values for all the tested temperatures, which is probably related with their similar water contents (11.0-11.4\%). On the other hand, [CHOL]Ac showed significantly lower apparent viscosity values, at all temperatures, when compared with the other ILs. This difference could be related with its higher water content (27.6\%). These results are supported by several studies that reported that the presence of water has a great impact on the ILs viscosity (Gómez, González, Domínguez, Tojo, \& Tojo, 2006; Seddon, Stark, \& Torres, 2007). In fact, the water content is an important parameter concerning the ionic liquids viscosity. Martins et al. (2016) reported for the same ILs, different apparent viscosity values as a function of their water content. For example, [CHOL]Ac with water contents of 23.39 and $33.16 \%$ had apparent viscosity values of 143 and $49 \mathrm{mPa} . s$, respectively, at $30^{\circ} \mathrm{C}$, thus confirming the effect of water content on the reduction of the ILs' apparent viscosity. It can also be observed that the ILs apparent viscosity is significantly reduced as the temperature was raised. The viscosity of ILs was reported to be dependent on the van der Waals and electrostatic forces between the anion and cation (Koi, Yahya, Abu Talip, \& Kurnia, 2019; Liu, Zhong, Xu, Kamali, \& Shi, 2018). Thus, the increase of temperature may affect those interactions, leading to a decrease of viscosity. This reduction is relevant for the dissolution procedure, since lower viscosity of the solvents ( $<30 \mathrm{mPa} . \mathrm{s}$ ) facilitates polymer dissolution.

\subsection{Preparation and characterization of the CGC polymeric structures}

Taking into account the decrease of both viscosity and density of the ILs with the increase of temperature, and based on previous studies, (Ardiyanti, 2014; de Oliveira, 2016) $\mathrm{CGC}_{\mathrm{KZ}}$ and CGC were exposed to each IL, under constant stirring, at 110 and $80^{\circ} \mathrm{C}$, respectively, for $24 \mathrm{~h}$. Following the water phase inversion method, distinct polymeric structures were obtained: $\mathrm{CGC}_{\mathrm{KZ}}$ yielded gels, while $\mathrm{CGC}_{\mathrm{p}}$ resulted in films (Fig. 3). This differing behaviour might be related with differences in the co-polymers' composition, namely, their GlcN content and DA. Moreover, the dissolution temperature might also contributed to the differing outcome.

\subsubsection{Fourier Transform-Infrared Analysis (FTIR)}

The films and gels FTIR spectra were compared, as well as the IL used for the dissolution of the polymers, [CHOL]Ac (Fig. 4a)), [CHOL] Prop (Fig. 4b)) and [CHOL]Hx (Fig. 4c)). The peaks around 1563, 1475 and $1390 \mathrm{~cm}^{-1}$ can be attributed to the IL structure, since they are not observed in the CGCs FTIR spectra (Fig. 1) but clearly identified in all polymeric structures (Fig. 4). The peak near $1563 \mathrm{~cm}^{-1}$ can be associated to the asymmetric stretching of carboxylates, the one around $1475 \mathrm{~cm}^{-1}$ is related to the $\mathrm{C}-\mathrm{H}$ stretching of the $\mathrm{CH}_{3}$ groups and the peak near $1390 \mathrm{~cm}^{-1}$ can be assigned to $\mathrm{C}-\mathrm{N}$ stretching vibrations (Foulet et al., 2016). The presence of these peaks indicates that some IL remained in the polymeric structure after the phase inversion. A new peak, near $1076-1082 \mathrm{~cm}^{-1}$ can be identified in the FTIR spectra of the CGCp-Ac and CGCp.prop films. This could be related with the deacetylation of chitin to chitosan. However, the peaks that distinguish chitin from chitosan, are located near $1556 \mathrm{~cm}^{-1}$ amide II $(\mathrm{N}-\mathrm{H}$ bending) and $1595 \mathrm{~cm}^{-1}\left(\mathrm{NH}_{2}\right.$ bending) (Dahmane, Taourirte, Eladlani, \& Rhazi, 2014), respectively, being overlapped with the IL characteristic peaks. In the case of the gels some changes are also observed with the appearance of three peaks near 1076, 1049 and $1008 \mathrm{~cm}^{-1}$, of much lower intensity that the ones of the CGCp films. 


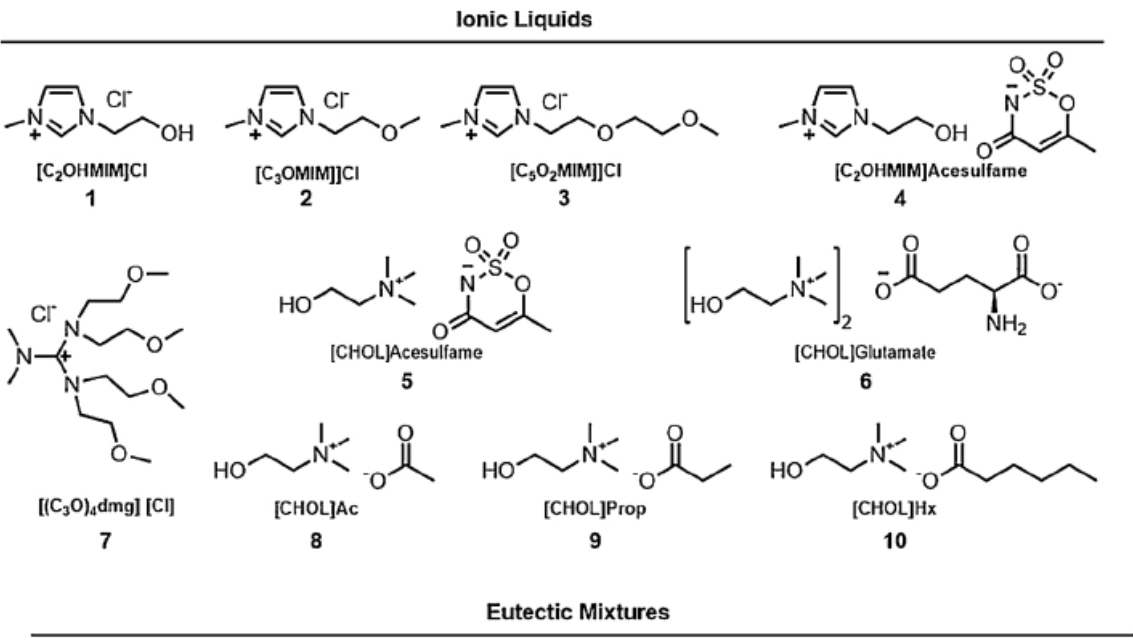<smiles>CC(C)C(=O)OC(C(=O)O)C(O)C(=O)O</smiles>

11<smiles>CC(C)(Cl)[N+](C)(C)CCO</smiles>

13<smiles>CC(N)=O</smiles><smiles>C[N+](C)(Cl)CCO</smiles>

12<smiles>CC(C)(Cl)[N+](C)(Cl)CCO</smiles>

(1:2)

Fig. 2. Structures of ILs and eutectic mixtures tested for dissolution of CGC.

Table 1

Water content of the synthetized cholinium-based ILs (measured at room temperature), ILs apparent viscosity and density at 30,80 and $110^{\circ} \mathrm{C}$.

\begin{tabular}{|c|c|c|c|c|c|c|c|}
\hline \multirow[t]{2}{*}{ Ionic Liquid } & \multirow[t]{2}{*}{ Water content $(\%)$} & \multicolumn{3}{|c|}{ Density ${ }^{a}\left(\mathrm{~g} / \mathrm{cm}^{3}\right)$} & \multicolumn{3}{|c|}{ Apparent viscosity (mPa.s) } \\
\hline & & $30^{\circ} \mathrm{C}$ & $80^{\circ} \mathrm{C}$ & $110^{\circ} \mathrm{C}$ & $30^{\circ} \mathrm{C}$ & $80^{\circ} \mathrm{C}$ & $110^{\circ} \mathrm{C}$ \\
\hline [CHOL]Ac & 27.6 & 1.093 & 1.065 & 1.047 & $38.94 \pm 0.14$ & $6.91 \pm 0.02$ & $3.59 \pm 0.01$ \\
\hline [CHOL]Prop & 11.0 & 1.077 & 1.049 & 1.032 & $245.78 \pm 0.86$ & $27.04 \pm 0.09$ & $11.62 \pm 0.04$ \\
\hline$[\mathrm{CHOL}] \mathrm{Hx}$ & 11.4 & 1.014 & 0.986 & 0.968 & $220.00 \pm 0.77$ & $26.53 \pm 0.09$ & $11.54 \pm 0.04$ \\
\hline
\end{tabular}

${ }^{\text {a }}$ The uncertainty of density measurements is $\pm 0.0001 \mathrm{~g} / \mathrm{cm}^{3}$.

\subsubsection{Glucosamine content and degree of acetylation}

As shown by the FTIR analysis (Fig. 4), some IL was retained in both polymeric structures (films and gels) after phase inversion with water and drying. The higher IL content observed in the gels $(27.56-49.56 \%)$ compared to the films $(<10 \%)$ (Table 2 ) may have contributed to the formation of such polymeric structures. Moreover, the IL content in the gels increased as the alkyl chain length increased. The presence of ILs in the gels is not a disadvantage since they are biocompatible and probably influence the polymeric structures' properties.

An increase of the GlcN content for all polymeric structures when compared with the pristine polymers was observed, although the change was much more significant for CGCp whose content increased from $28.0 \pm 0.1 \%$ to above $50 \%$ (Table 2). This could be a result of a depolymerization of the glucan moiety of $\mathrm{CGC}_{\mathrm{p}}$ during exposure to the ILs at high temperatures, leading to the generation of glucose monomers or glucan oligomers, which were washed from the polymeric structure during the phase inversion procedure.

For $\mathrm{CGC}_{\mathrm{p}}$ films, a decrease of the DA was observed for $\mathrm{CGC}_{\mathrm{p}-\mathrm{Ac}}$ $(14.3 \pm 1.6 \%)$ and $\mathrm{CGC}_{\text {p.prop }}(34.3 \pm 0.6 \%)$ films, while for $\mathrm{CGC}_{\text {p-Hx }}$ film the DA remained almost unchanged $(70.8 \pm 0.8 \%)$. These results indicate that after phase inversion the final structures of $\mathrm{CGC}_{\mathrm{p}-\mathrm{Ac}}$ and CGC $_{\text {p-prop }}$ contain chitosan-glucan complex (ChGC) instead of chitinglucan complex (CGC). This can be a result of the hydrolysis of acetylgroup of chitin promoted by the ionic liquids, during the dissolution 


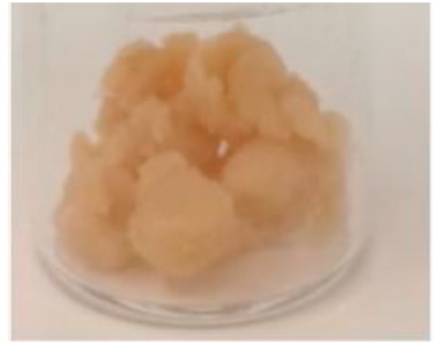

$\mathrm{CGC}_{\mathrm{KZ}} \mathrm{Gel}$

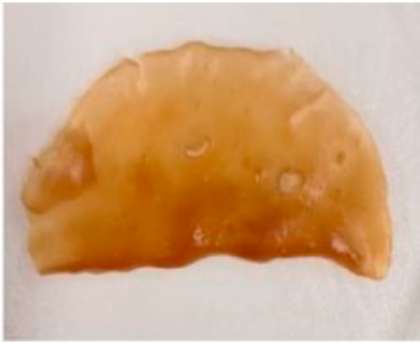

$\mathrm{CGC}_{\mathrm{P}}$ Film

Fig. 3. Images of the resulting CGC polymeric structure after phase inversion with water.

procedures at elevated temperatures. A similar phenomenon has already been reported for chitin dissolved in pyridinium-based ionic liquids, at $80^{\circ} \mathrm{C}$. FTIR analysis of the regenerated chitin showed the reduction of the polymer's DA and the formation of quaternary ammonium chitosan (Taheri, Abdolmaleki, \& Fashandi, 2018). The calculation for the DA of the $\mathrm{CGC}_{\mathrm{KZ}}$ gels yielded negative values, according to Eq. 2 (Section 2.2.1), thus suggesting the complete deacetylation of $\mathrm{CGC}_{\mathrm{KZ}}$ has occurred. This result may be due to the higher temperature that the co-polymer was exposed during the dissolution procedure $\left(110^{\circ} \mathrm{C}\right)$.

\subsection{Films characterization}

\subsubsection{Scanning Electron Microscopy (SEM)}

SEM analysis was performed in order to have a better understanding of the obtained CGC films morphology. Unfortunately, both CGCp-Ac and $\mathrm{CGC}_{\mathrm{p}-\mathrm{Hx}}$ films became distorted upon the application of the Au-Pd layer, necessary for the performance of this analysis, which turned impossible the analysis of the cross-section images. From the surface SEM images (Fig. 5a)-c)), it is possible to observe that all the films present a dense and homogeneous surface with no visible agglomerates

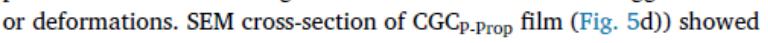
a homogeneous and compact structure without any deformations or pores. These results indicate the existence of a good compatibility between the polymer and the used solvents, confirming the successful dissolution of CGC in the three cholinium-based ILs solvents. A similar
Table 2

IL amount in CGC polymeric structures after phase inversion and GlcN content of CGC polymers and resulting polymeric structures.

\begin{tabular}{lll}
\hline Sample & IL amount in CGC polymeric structures (\%wt.) & GlcN content (\%) \\
\hline CGC $_{\text {KZ }}$ & - & $50.5 \pm 0.2$ \\
CGC $_{\mathrm{p}}$ & - & $28.0 \pm 0.1$ \\
CGC $_{\text {KZ-Ac }}$ & 27.56 & $58.5 \pm 0.4$ \\
CGC $_{\text {KZ-Prop }}$ & 34.03 & $57.8 \pm 0.2$ \\
CGC $_{\text {KZ-Hx }}$ & 49.56 & $60.8 \pm 0.3$ \\
CGC $_{\text {p-Ac }}$ & 9.35 & $54.9 \pm 0.2$ \\
CGC-Ar & n.d. $^{\text {a }}$ & $56.4 \pm 0.5$ \\
CGC-Hx & 0.33 & $53.4 \pm 0.3$ \\
\hline
\end{tabular}

${ }^{\text {a }}$ n.d. - not determined.

microstructure was reported by Duan, Chang, and Zhang (2014)) for chitin films obtained through the dissolution of chitin with a $\mathrm{NaOH}$ / urea aqueous system, followed by immersion in a coagulation bath to remove the solvent.

\subsubsection{Contact angles}

$\mathrm{CGC}_{\text {p-Ac }}$ and $\mathrm{CGC}_{\text {p-Prop }}$ films showed a hydrophilic behaviour, with contact angles of $70.0 \pm 3.4^{\circ}$ and $79.2 \pm 6.2^{\circ}$, respectively, while CGC $_{\mathrm{p}-\mathrm{Hx}}$ showed a more hydrophobic behaviour with a contact angle of $90.2 \pm 2.4^{\circ}$. From FTIR spectra (Fig. 4a)-c)) it has been concluded that some IL remained in the polymeric matrix after phase inversion, which indicates the establishment of interactions between the IL and the

$$
\text { a) }
$$

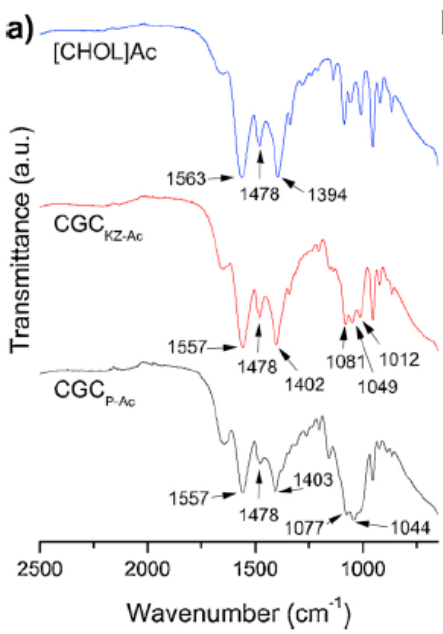

b)

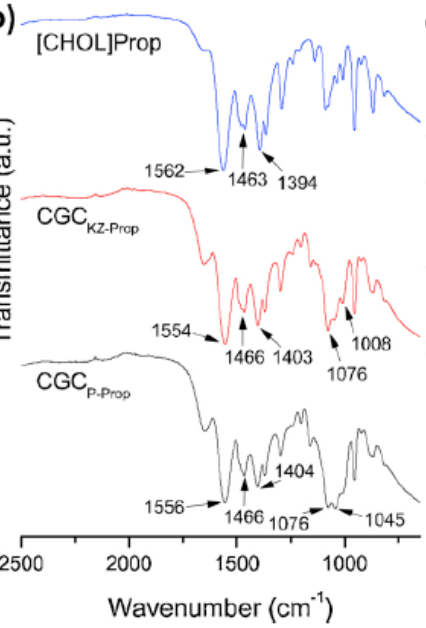

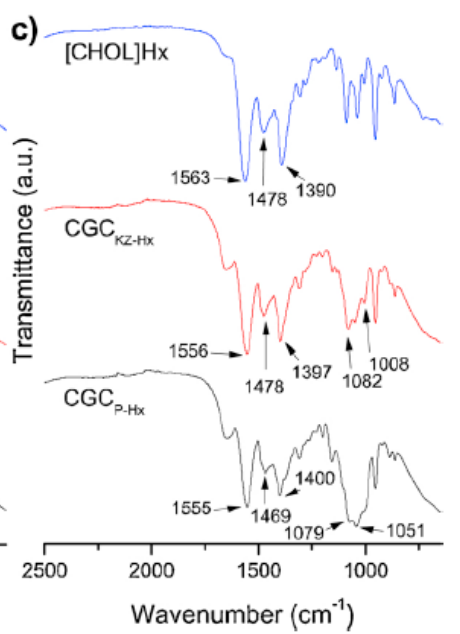

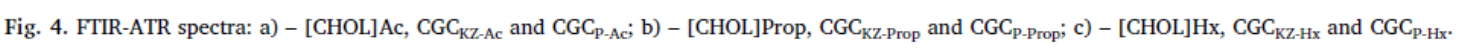



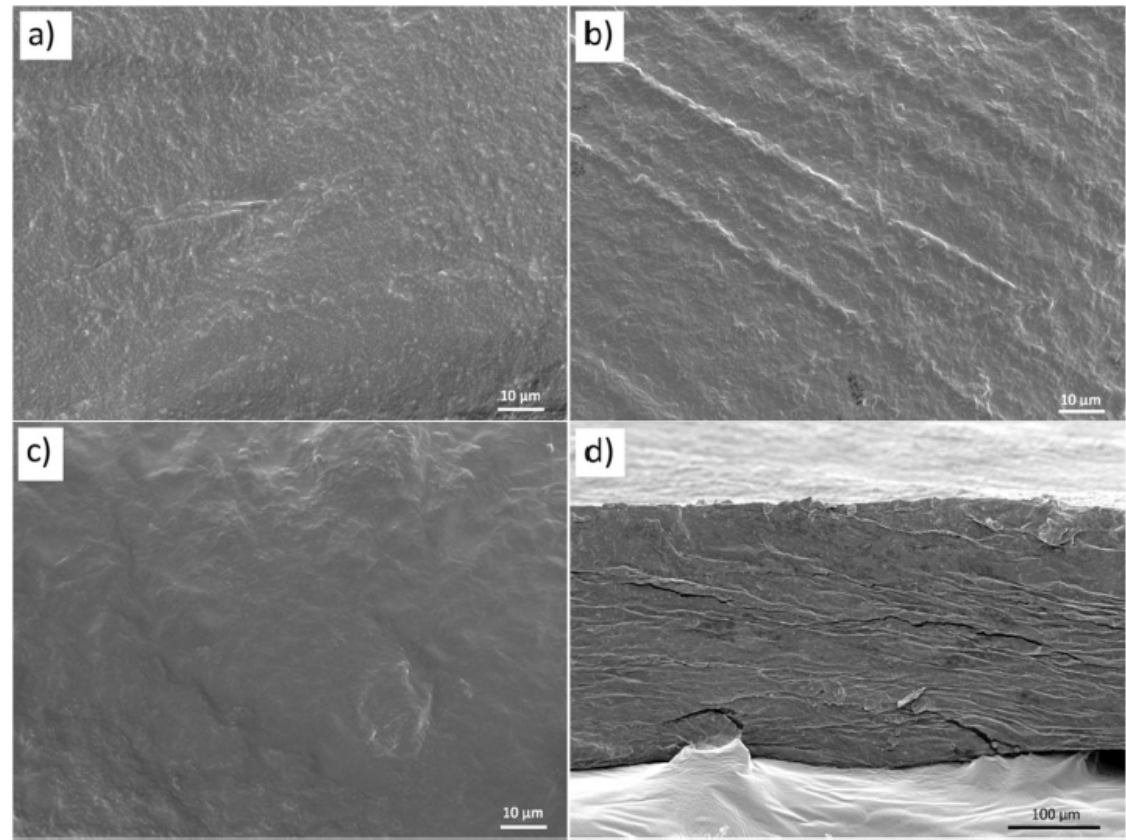

Fig. 5. SEM images of CGC $_{p}$ films: a) CGCp-Ac film surface (magnification x1000); b) CGC $_{\text {p-prop }}$ film surface (magnification x1000); c) CGCp-Hx film surface (magnification x1000); d) CGC $C_{\text {p-prop }}$ film cross-section (magnification x200).

Table 3

Puncture tests results of $\mathrm{CGC}_{\mathrm{p}}$ films.

\begin{tabular}{lllll}
\hline Sample & Thickness $(\mathrm{mm})$ & Tensile strength $(\mathrm{MPa})$ & Normalised tensile strength $(\mathrm{MPa} / \mathrm{mm})$ & Elongation $(\%)$ \\
\hline CGC & & & \\
CGC-Ac & $0.143 \pm 0.014$ & $0.484 \pm 0.059$ & $3.394 \pm 0.531$ & $39.8 \pm 2.4$ \\
CGC Pr-Hx & $0.106 \pm 0.014$ & $0.203 \pm 0.008$ & $1.910 \pm 0.263$ & $38.6 \pm 1.1$ \\
\hline
\end{tabular}

polymer. These interactions resulted in the formation of hydrogen bonds between the acetamido and hydroxyls groups of CGC and the carboxylate anion of the ILs (Uto, Idenoue, Yamamoto, \& Kadokawa, 2018). Thus, an increase of the free volume between the polymer chains and a reduction of the active sites occurs, leading to a reduction in surface free energy which results in higher contact angles (Hameed, Guo, Tay, \& Kazarian, 2011; Pang, Liu, Zhang, Wu, \& Sun, 2013; Wang et al., 2015). The difference in the contact angles of the CGC films can be related to the interaction between water and the IL used for CGC dissolution. Interaction with water was reported to be strongly dependent on the anion alkyl chain length (Tran, Lacerda, \& Oliveira, 2003). For smaller anions, the alkyl chains tend to be more at the surface promoting an higher interaction with water molecules and the formation of hydrogen bonds (Di Francesco et al., 2011). In this work, the size of anion increases in this order, acetate $<$ propionate $<$ hexanoate so the observed behaviour was expected.

\subsubsection{Water swelling capacity}

CGC $_{\text {p-Ac }}$ film showed the highest swelling degree (300 $\left.\pm 7 \% \mathrm{w} / \mathrm{w}\right)$, followed by the CGC $\mathrm{C}_{\text {prop }}$ film $(269 \pm 19 \% \mathrm{w} / \mathrm{w})$ and the $\mathrm{CGC}_{\mathrm{p} \text {-Hx }}$ $(257 \pm 21 \% \mathrm{w} / \mathrm{w})$. Since the difference between the polymeric structures is the IL used in the polymer dissolution, it means that the IL anion alkyl chain plays a role in the swelling behaviour of the films. These results are in accordance with the contact angles results where the CGCp-Ac shows to be the film with the highest affinity with water, possessing the lowest contact angle. Thus, it shows a relation between the sample hydrophilicity and its swelling behaviour may exist. King et al. (2017) produced chitin films using $\left[\mathrm{C}_{2} \mathrm{mim}\right][\mathrm{OAc}]$ as solvent and different drying methods. The resultant films presented a swelling between $504 \%(w / w)$ and $777 \%(w / w)$, which is higher than the values of this work. The lower swelling values can be related to the presence of some IL in the polymeric matrix, which can compete with the absorption of water molecules.

\subsubsection{Puncture tests}

Tensile strength and elongation were determined through puncture tests in order to evaluate the mechanical properties of the produced films. Since the films possessed different thickness values, for a viable comparison between each film, the normalised puncture strength was calculated (Table 3). In addition, to complement the analysis of the samples' mechanical behaviour stress-strain curves were represented (Fig. S1 - Supplementary Material). The highest value of tensile strength and elongation at break was obtained for CGCp-Ac film with $3.394 \mathrm{MPa}$ / $\mathrm{mm}$ and $39.8 \%$, respectively. It is observed a decrease of the elongation percentage with the increase of the alkyl chain length. This behaviour can be associated with the fact that the increase of alkyl chain-length lead to higher polymer-polymer interactions which resulted in the decrease of the films' ability to deform. For the puncture strength, the CGCp-Ac and the $\mathrm{CGC}_{\mathrm{p}-\mathrm{Hx}}$ films have a higher value than the CGCp-prop. However, it can be observed that the error associated to the measurement of both $\mathrm{CGC}_{\mathrm{p}-\mathrm{Ac}}$ and $\mathrm{CGC}_{\mathrm{p}-\mathrm{Hx}}$ is 2 times higher comparing with

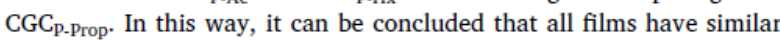
puncture strength. Abdel-mohsen et al. (2016) reported chitin/chitosan-glucan complex fibers/nonwoven mat produced using the $\mathrm{NaOH}$ / urea aqueous system, which presented a lower elongation at break (1.2-3.5 \%). Chitin films produced using $\mathrm{NaOH}$ /urea aqueous system 
presented higher tensile strength ( $30-111 \mathrm{MPa})$, although with lower elongation (2.9-6.4\%) that only increased through the addition of a crosslinker (Duan et al., 2013; Zhu et al., 2019). On the other hand, Tomé et al. (2015) produced chitosan-cholinium carboxylate ionic liquid films which presented both tensile strength and elongation at break higher than the films produced in this work. The increase of the elongation at break, comparing with the pure chitosan films, was related with the plasticizing effect of the ILs when present in the polymeric structure.

In this work, the presence of non-removed IL in the structure of the polymer may induce a higher free volume between the polymer chains, which results in a low tensile strength, but on other hand forming more deformable structures, resulting in a higher elongation at break. Comparing with some commercially available polyurethane foam-films for wound dressing, the films produced in this work presented similar tensile strength, but an elongation at break at least five times lower, with the tested polyurethane foam-films presenting an elongation between $180 \%$ and $1101 \%$ (Lee et al., 2016). Tissucol/Tissel, which is a commercial surgical fibrin glue widely used, presented a lower tensile strength of $0.141 \pm 0.019 \mathrm{MPa}$, but a higher elongation at break (363.1 $\pm 30.6 \%$ ). On other hand, Glubran2, which is also a surgical glue, presented a high value of tensile strength, than the CGCp films, $(20.44 \pm 2.83 \mathrm{MPa})$, but a lower elongation at break (13.2 $\pm 4.3 \%)$ (Kull et al., 2009).

\subsection{Gels characterization}

\subsubsection{Rheology tests}

Rheology tests were performed to understand the effect of the relative humidity in the viscoelastic properties of the developed gels. Firstly, stress sweep measurements were performed to estimate the linear viscoelastic region and determine a suitable tension to perform the frequency sweeps. All CGC gels presented a similar behaviour and a tension between $5 \mathrm{~Pa}$ and $10 \mathrm{~Pa}$ was chosen to perform the frequency sweeps. In this analysis, G', storage moduli, represents the energy stored by a sample (elastic behaviour) and G", loss moduli, is a measure of the energy lost by the sample during the shear process (viscous behaviour) (Jătariu et al., 2013; Mezger, 2011). The strength of a gel may be related to the magnitude of $G$ ', through the difference between the values of G' and G' and from the dependence of both variables with frequency (Chenite, Buschmann, Wang, Chaput, \& Kandani, 2001). As it can be seen in Fig. 6, all $\mathrm{CGC}_{\mathrm{KZ}}$ gels mechanical spectra show a predominant elastic behaviour with the storage modulus ( $G^{\prime}$ ) having values one order of magnitude higher than the loss modulus (G"), which is common of gel-type materials, independently of the relative humidity and IL used for the dissolution. Also, these gels present the typical behaviour of weak gel materials with both variables (G' and G") being dependent on the frequency. This behaviour is in accordance with previous works where CGC hydrogels were also developed (Araújo, Alves et al., 2019).

In order to make a better analysis of the rheological behaviour of the gels, their water content after conditioning was measured. It is possible to observe a decrease in the water content of the gels with decreasing conditioning relative humidity (Table 4 ). This fact may be attributed to the hygroscopic behaviour of the gel. Correlating the water contents to the mechanical spectra, it can be noticed that, the lowest relative humidity $\left(\mathrm{CH}_{3} \mathrm{COOK}-\mathrm{RH}: 21.6 \%\right)$ leads to gels with the lowest water content on their structure. Those gels present the highest G' values, independently of the IL used for dissolution. When looking to the gels submitted to the other three relative humidity values, in general, they present similar values of G'. Nevertheless, it was expected that G' values decreased with the increase of the water content in the gels as it may act as plasticizer. Though, this only occurs for the $\mathrm{CGC}_{\mathrm{KZ}-\mathrm{Hx}}$ gels. This fact can be explained by the existence of water gradients through the gels after conditioning that may mask the real effect of water, as well as the effect of the type of IL used, on gels' mechanical properties. Nevertheless, the results show that the water content plays an important role
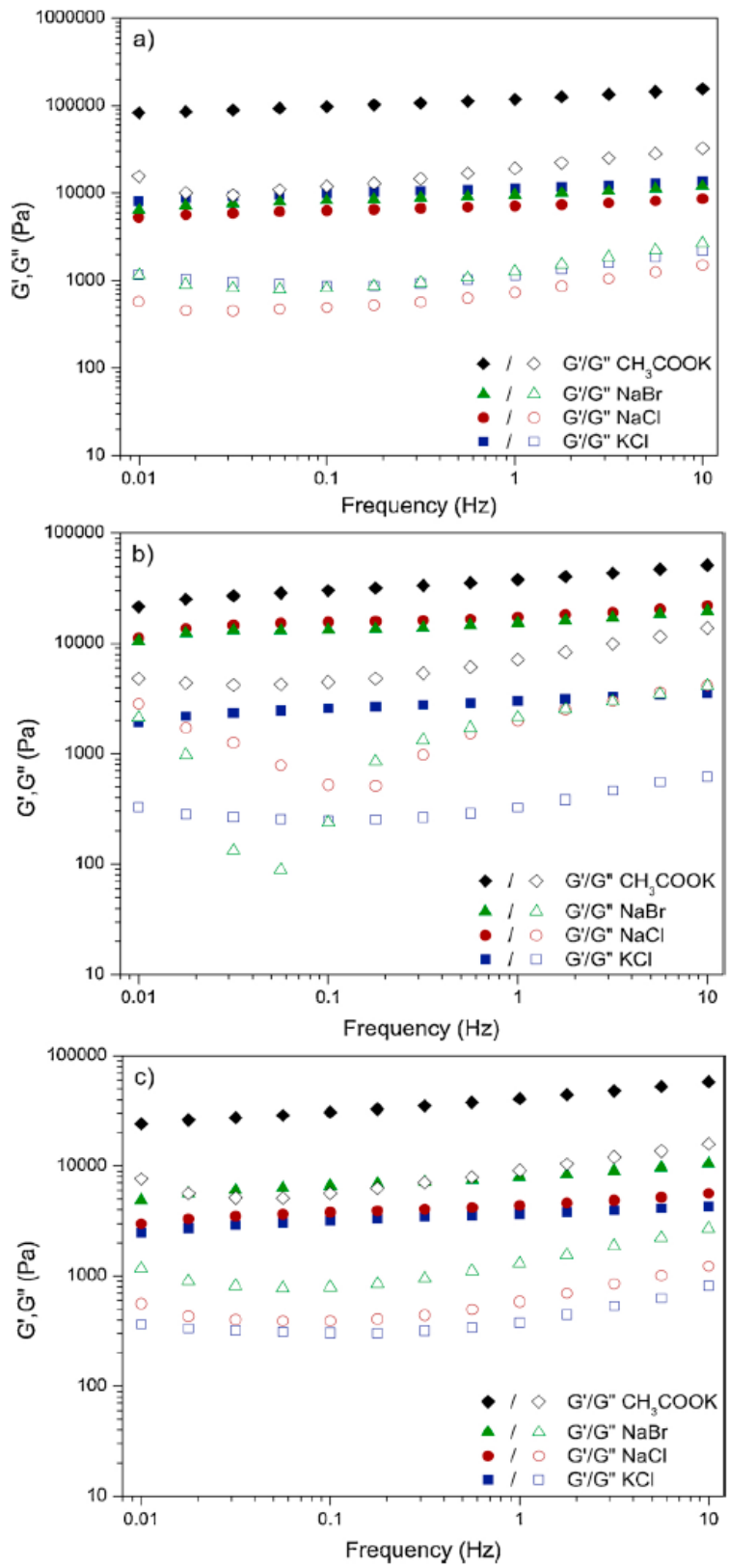

Fig. 6. Frequency sweeps of $\mathrm{CGC}_{\mathrm{KZ}}$ gels stabilized at different relative humidity values: a) $\mathrm{CGC}_{\mathrm{KZ}-\mathrm{Ac}}$, b) $\mathrm{CGC}_{\mathrm{KZ}-\mathrm{P} \text { rop }}$ and c) $\mathrm{CGC}_{\mathrm{KZ}-\mathrm{Hx}}$

Table 4

Water content of gels after conditioning at different relative humidity values.

\begin{tabular}{lllll}
\hline \multirow{2}{*}{ Gels } & \multicolumn{4}{l}{ Water content after conditioning (\%) } \\
\cline { 2 - 5 } & $\mathrm{KCl}(\mathrm{RH}-83.6$ & $\mathrm{NaCl}(\mathrm{RH}$ & $\mathrm{NaBr}(\mathrm{RH}-$ & \multicolumn{1}{l}{ CH3COOK (RH } \\
& $\%$ ) & $-75.1 \%)$ & $56.0 \%)$ & $-21.6 \%)$ \\
\hline CGC $_{\text {KZ-Ac }}$ & $53.0 \pm 0.5$ & $46.3 \pm 0.5$ & $38.0 \pm 0.4$ & $18.1 \pm 0.2$ \\
CGC $_{\text {KZ-Prop }}$ & $53.8 \pm 0.5$ & $43.2 \pm 0.4$ & $35.8 \pm 0.4$ & $21.5 \pm 0.2$ \\
CGC KZ-Hx & $46.1 \pm 0.5$ & $36.6 \pm 0.4$ & $29.7 \pm 0.3$ & $17.5 \pm 0.2$ \\
\hline
\end{tabular}


in the viscoelastic properties of the $\mathrm{CGC}_{\mathrm{KZ}}$ gels, with low water contents (below $22 \%$ ) definitely producing stronger biopolymeric structures.

\section{Conclusions}

This work reported the dissolution of CGC from two different origins, namely, the cell-walls of the yeast Komagataella pastoris and of the fungus Aspergillus niger, using biocompatible cholinium-based ILs. The CGC samples differed in terms of GlcN content $(28.0 \pm 0.1 \%$ and $50.5 \pm 0.2 \%$, respectively), which probably influenced the type of polymeric structure obtained upon dissolution in the ILs and coagulation by phase inversion in water. $K$. pastoris derived CGC yielded standalone films, while A. niger CGC resulted in weak gels. After being exposed to the ILs, a decrease of CGC's glucan moiety and a reduction of the DA were observed, resulting in chitosan-glucan complexes (ChGC). Both films and gels retained an amount of ILs in their structures, which was shown to play a role on the physical properties of the polymeric structures. The CGC films presented a dense and flexible structure with good mechanical properties. Regarding CGC gels, they behaved as weak gels, being their viscoelastic properties dependent on the water content. Due to their biocompatibility and also tailorable physical and chemical properties by changing the IL used for CGC dissolution, both biopolymeric structures (films and gels) may be considered promising materials for biomedical applications.

\section{CRediT authorship contribution statement}

Inês C. Ferreira: Conceptualization, Investigation, Writing - original draft. Diana Araújo: Investigation. Pierre Voisin: Investigation. Vítor D. Alves: Investigation. Andreia A. Rosatella: Investigation. Carlos A.M. Afonso: Writing - review \& editing. Filomena Freitas: Writing - review \& editing. Luísa A. Neves: Conceptualization, Writing - review \& editing, Supervision.

\section{Acknowledgements}

This work was supported by the Associated Laboratory for Green Chemistry - LAQV, Applied Molecular Biosciences Unit - UCIBIO and Linking Landscape, Environment, Agriculture and Food research unit, which are financed by national funds from FCT/MCTES (UIDB/50006/ 2020, UIDB/04378/2020 and PEst-OE/AGR/UI0245/2020, respectively). Funding from the projects PTDC/CTM-CTM/29869/2017 and UID/DTP/04138/2019 funded by FCT/MCTS are also acknowledged. Luísa A. Neves, Inês C. Ferreira and Diana Araújo acknowledge FCT/ MCTES for financial support through FCT Investigator contract IF/ 00505/2014 and $\mathrm{PhD}$ fellowships SFRH/BD/137636/2018 and SFRH/ $\mathrm{BD} / 140829 / 2018$, respectively.

\section{Appendix A. Supplementary data}

Supplementary material related to this article can be found, in the online version, at doi:https://doi.org/10.1016/j.carbpol.2020.116679.

\section{References}

Abdel-mohsen, A. M., Jancar, J., Massoud, D., Fohlerova, Z., \& Elhadidy, H. (2016). Novel chitin/chitosan-glucan wound dressing: Isolation, characterization, antibacterial activity and wound healing properties. Intermational Journal of Pharmaceutics, 510(1), tivity and

Araújo, D., Freitas, F., Sevrin, C., Grandfils, C., \& Reis, M. A. M. (2017). Co-production of chitin-glucan complex and xylitol by Komagataella pastoris using glucose and xylose mixtures as carbon source. Carbohydrate Polymers, 166, 24-30.

Araújo, J. M. M., Florindo, C., Pereiro, A. B., Vieira, N. S. M., Matias, A. A., Duarte, C. M. M., ... Marrucho, I. M. (2014). Cholinium-based ionic liquids with pharmaceutically active anions. RSC Advances, 4(53), 28126-28132.

Araújo, D., Alves, V. D., Lima, S. A. C., Reis, S., Freitas, F., \& Reis, M. A. M. (2019). Novel hydrogels based on yeast chitin-glucan complex: Characterization and safety assessment. Intermational Journal of Biological Macromolecules. https://doi.org/10.1016/]. ijbiomac.2019.11.141.
Araújo, D., Ferreira, I. C., Torres, C. A. V., Neves, L., \& Freitas, F. (2019). Chitinous polymers: Extraction from fungal sources, characterization and processing towards value-added applications. Journal of Chemical Technology \& Biotechnology, 95(5), $1277-1289$.

Ardiyanti, R. (2014). Design and characterization of chitin- glucan polymeric structures for wound dressing materials. Master thesis, Retrieved fromFaculdade de Ciências e Tecnologia - Universidade NOVA de Lisboahttp://hdl.handle.net/10362/13306.

B. Barrera, O. Beltran, \& G. Diosa, (2016). US Pat., 20160122444A1. Santiago de Cali.

B. Barrera, O. Beltran, \& G. Diosa, (2016). US Pat., 20160122444A1. Santiago de Cali.
Becherini, S., Mezzetta, A., Chiappe, C., \& Guazzelli, L. (2019). Levulinate amidinium protic ionic liquids (PILs) as suitable media for the dissolution and levulination of cellulose. New Journal of Chemistry, 43(11), 4554-4561.

Beran, K., Holan, Z., \& Baldrián, J. (1972). The chitin-glucan complex of Saccharomyces cerevisiae. Folia Microbiologica, 17, 322-330.

Bornet, A., \& Teissedre, P. L. (2008). Chitosan, chitin-glucan and chitin effects on minerals (iron, lead, cadmium) and organic (ochratoxin A) contaminants in wines. European Food Research and Technology, 226(4), 681-689.

Cárdenas, G., Cabrera, G., Taboada, E., \& Miranda, S. P. (2004). Chitin characterization by SEM, FTIR, XRD, and ${ }^{13} \mathrm{C}$ cross polarization/mass angle spinning NMR. Jourmal of Applied Polymer Science, 93(4), 1876-1885.

Chen, W., Xue, Z., Wang, J., Jiang, J., Zhao, X., \& Mu, T. (2018). Investigation on the thermal stability of deep eutectic solvents. Acta Physico - Chimica Sinica, 34(8), 904-911.

Chenite, A., Buschmann, M., Wang, D., Chaput, C., \& Kandani, N. (2001). Rheological characterisation of thermogelling chitosan/glycerol-phosphate solutions. Carbohydrate Polymers, 46, 39-47.

Corradi da Silva, M. L., Fukuda, E. K., Vasconcelos, A. F. D., Dekker, R. F. H., Matias, A. C., Monteiro, N. K., ... Carbonero, E. R. (2008). Structural characterization of the cell wall d-glucans isolated from the mycelium of Botryosphaeria rhodina MAMB-05. Carbohydrate Research, 343(4), 793-798.

Dahmane, E. M., Taourirte, M., Eladlani, N., \& Rhazi, M. (2014), Extraction and characterization of chitin and chitosan from Parapenaeus longirostris from Moroccan local sources. International Journal of Polymer Analysis and Characterization, 19(4), 342-351.

de Oliveira, A. F. R. (2016). Development of chitin-glucan polymeric structures using biocompatible ionic liquids. Master thesis, Retrieved fromFaculdade de Ciências e Tecnologia - Universidade NOVA de Lisboahttps://run.unl.pt/handle/10362/19560.

Di Francesco, F., Calisi, N., Creatini, M., Melai, B., Salvo, P., \& Chiappe, C. (2011). Wate sorption by anhydrous ionic liquids. Green Chemistry, 13(7), 1712-1717.

Duan, B., Chang, C., Ding, B., Cai, J., Xu, M., Feng, S., ... Zhang, L. (2013). High strength films with gas-barrier fabricated from chitin solution dissolved at low temperature Journal of Materials Chemistry A, 1(5), 1867-1874

Duan, B., Chang, C., \& Zhang, L. (2014). Structure and properties of films fabricated from chitin solution by coagulating with heating. Journal of Applied Polymer Science, 131(4), 1-7.

EFSA Panel on Dietetic Products Nutrition and Allergies (2010). Scientific opinion on the safety of 'Chitin - glucan' as a novel food ingredient. EFSA Journal, 8(7), 1-17.

Farinha, I., Duarte, P., Pimentel, A., Plotnikova, E., Chagas, B., Mafra, L., ... Reis, M. A. M. (2015). Chitin-glucan complex production by Komagataella pastoris: Downstream optimization and product characterization. Carbohydrate Polymers, 130, 455-464.

Farinha, I., Freitas, F., \& Reis, M. A. M. (2017). Implementation of a repeated fed-batch process for the production of chitin-glucan complex by Komagataella pastoris. New Biotechnology, 37, 123-128.

Feofilova, E. P., Nemtsev, D. V., Tereshina, V. M. \& Memorskaya, A. S. (2006) Developmental change of the composition and content of the chitin-glucan complex in the fungus Aspergillus niger. Applied Biochemistry and Microbiology, 42(6), 545-549.

Foulet, A., Ghanem, O. B., El-Harbawi, M., Lévêque, J. M., Mutalib, M. I. A., \& Yin, C. Y. (2016). Understanding the physical properties, toxicities and anti-microbial activities of choline-amino acid-based salts: Low-toxic variants of ionic liquids. Journal of Molecular Liquids, 221, 133-138.

Frade, R. F. M., \& Afonso, C. A. M. (2010). Impact of ionic liquids in environment and humans: An overview. Human \& Experimental Toxicology, 29(12), 1038-1054.

Frade, R. F. M., Rosatella, A. A., Marques, C. S., Branco, L. C., Kulkarni, P. S., Mateus, N. M. M., ... Duarte, C. M. M. (2009). Toxicological evaluation on human colon carcinoma cell line (CaCo-2) of ionic liquids based on imidazolium, guanidinium, ammonium, phosphonium, pyridinium and pyrrolidinium cations. Green Chemistry, 11(10), 1660-1665.

Gautier, S., Xhauflaire-Uhoda, E., Gonry, P., \& Piérard, G. E. (2008). Chitin - glucan, a natural cell scaffold for skin moisturization and rejuvenation. International Journal of Cosmetic Science, 30, 459-469.

Gómez, E., González, B., Domínguez, Á., Tojo, E., \& Tojo, J. (2006). Dynamic viscositie of a series of 1-alkyl-3-methylimidazolium chloride ionic liquids and their binary mixtures with water at several temperatures. Journal of Chemical and Engineering Data, 51(2), 696-701. https://doi.org/10.1021/je050460d.

González-Rivera, J., Husanu, E., Mero, A., Ferrari, C., Duce, C., Tinè, M. R., ... Guazzelli, L. (2020). Insights into microwave heating response and thermal decomposition behavior of deep eutectic solvents. Journal of Molecular Liquids, 300, Article 112357.

Greenspan, L. (1977). Humidity fixed points of binary satured aqueous solutions. Journal of Research of the National Bureau of Standards - A. Physics and Chemistry, 81A(1), 89-96.

Gunaratne, H. Q. N., Seddon, K. R., Rebelo, L. P. N., Petkovic, M., Ferguson, J. L., Leitão, M. C., ... Pereira, C. S. (2010). Novel biocompatible cholinium-based ionic liquids-Toxicity and biodegradability. Green Chemistry, 12(4), 643.

Hameed, N., Guo, Q., Tay, F. H., \& Kazarian, S. G. (2011). Blends of cellulose and poly(3hydroxybutyrate-co-3-hydroxyvalerate) prepared from the ionic liquid 1-butyl-3methylimidazolium chloride. Carbohydrate Polymers, 86(1), 94-104.

Hirano, A., Shiraki, K., \& Arakawa, T. (2012). Polyethylene glycol behaves like weak 
organic solvent. Biopolymers, 97(2), 117-122.

Ivshin, V. P., Artamonova, S. D., Ivshina, T. N., \& Sharnina, F. F. (2008). Methods for isolation of chitin-glucan complexes from higher fungi native biomass. Polymer Science Series B, 49(11-12), 305-310.

Jang, M.-K., Kong, B.-G., Jeong, Y.-I., Lee, C. H., \& Nah, J.-W. (2004). Physicochemical characterization of $\alpha$-chitin, $\beta$-chitin, and $\gamma$-chitin separated from natural resources. Journal of Polymer Science Part A: Polymer Chemistry, 42(14), 3423-3432.

Jătariu, A. N., Danu, M., Peptu, C. A., Ioanid, G., Ibanescu, C., \& Popa, M. (2013). Ionically and covalently cross-linked hydrogels based on gelatin and chitosan. Soft Materials, 11(1), 45-54.

Jayakumar, R., Prabaharan, M., Sudheesh Kumar, P. T., Nair, S. V., Furuike, T., \& Tamura, $\mathrm{H}$. (2011). Novel chitin and chitosan materials in wound dressing. In A. Laskovski (Ed.). Biomedical engineering, trends in materials science (pp. 3-24). London: InTech.

Kaya, M., Erdogan, S., Mol, A., \& Baran, T. (2015). Comparison of chitin structures isolated from seven Orthoptera species. International Journal of Biological Macromolecules, 72, 797-805.

King, C., Shamshina, J. L., Gurau, G., Berton, P., Khan, N. F. A. F., \& Rogers, R. D. (2017). A platform for more sustainable chitin films from an ionic liquid process. Green Chemistry, 19(1), 117-126.

Koi, Z. K., Yahya, W. Z. N., Abu Talip, R. A., \& Kurnia, K. A. (2019). Prediction of the viscosity of imidazolium-based ionic liquids at different temperatures using the quantitative structure property relationship approach. New Joumal of Chemistry, 43(41), 16207-16217.

Kull, S., Martinelli, I., Briganti, E., Losi, P., Spiller, D., Tonlorenzi, S., \& Soldani, G. (2009). Glubran2 surgical glue: In vitro evaluation of adhesive and mechanical properties. The Journal of Surgical Research, 157(1), e15-e21.

Lee, S. M., Park, I. K., Kim, Y. S., Kim, H. J., Moon, H., Mueller, S., \& Jeong, Y. I. L. (2016). Physical, morphological, and wound healing properties of a polyurethane foam-film dressing. Biomaterials Research, 20(1), 1-11.

Lehtovaara, B. C., \& Gu, F. X. (2011). Pharmacological, structural, and drug delivery properties and applications of 1,3- $\beta$-glucans. Journal of Agricultural and Food Chemistry, 59(13), 6813-6828.

Li, X., Li, H., Ling, Z., Xu, D., You, T., Wu, Y. Y., \& Xu, F. (2020). Room-temperature superbase-derived ionic liquids with facile synthesis and low viscosity: Powerful solvents for cellulose dissolution by destroying the cellulose aggregate structure. Macromolecules, 53(9), 3284-3295.

Liu, F., Zhong, X., Xu, J., Kamali, A., \& Shi, Z. (2018). Temperature dependence on density, viscosity, and electrical conductivity of ionic liquid 1-ethyl-3-methylimidazolium fluoride. Applied Sciences, 8(3), 356.

Lu, Y., Sun, Q., She, X., Xia, Y., Liu, Y., Li, J., \& Yang, D. (2013). Fabrication and characterisation of $\alpha$-chitin nanofibers and highly transparent chitin films by pulsed ultrasonication. Carbohydrate Polymers, 98(2), 1497-1504.

Lynam, J. G., Kumar, N., \& Wong, M. J. (2017). Deep eutectic solvents' ability to solubilize lignin, cellulose, and hemicellulose; thermal stability; and density. Bioresource Technology, 238, 684-689.

Martins, C. F., Neves, L. A., Estevão, M., Rosatella, A., Alves, V. D., Afonso, C. A. M., Coelhoso, I. M. (2016). Effect of water activity on carbon dioxide transport in cholinium-based ionic liquids with carbonic anhydrase. Separation and Purification Technology, 168, 74-82.

Martins, M. A. R., Pinho, S. P., \& Coutinho, J. A. P. (2019). Insights into the nature of eutectic and deep eutectic mixtures. Journal of Solution Chemistry, 48(7), 962-982.

Mezger, T. G. (2011). The Rheology handbook (3rd ed.). Hanover, Germany: Vincentz Network GmbH \& Co. KG (Chapter 8).

Muhammad, N., Hossain, M. I., Man, Z., El-Harbawi, M., Bustam, M. A., Noaman, Y. A., Yin, C.-Y. (2012). Synthesis and physical properties of choline carboxylate ionic liquids. Journal of Chemical and Engineering Data, 57, 2191-2196.

Nwe, N., Stevens, W. F., Tokura, S., \& Tamura, H. (2008). Characterization of chitosan and chitosan-glucan complex extracted from the cell wall of fungus Gongronella butler USDB 0201 by enzymatic method. Enzyme and Microbial Technology, 42(3), 242-251.

Pang, J., Liu, X., Zhang, X., Wu, Y., \& Sun, R. (2013). Fabrication of cellulose film with enhanced mechanical properties in ionic liquid 1-allyl-3-methylimidaxolium chloride (AmimCl). Materials, 6(4), 1270-1284.

Pestov, A. V., Drachuk, S. V., Koryakova, O. V., \& Yatluk, Y. U. G. (2009). Isolation and characterization of chitin-glucan complexes from the mycothallus of Fungi belonging to Russula genus. Chemistry for Sustainable Development, 17, 281-287.

Petkovic, M., Seddon, K. R., Rebelo, L. P. N., \& Pereira, C. S. (2011). Ionic liquids: A pathway to environmental acceptability. Chemical Society Reviews, 4O(3), 1383-1403.

Poirier, M., \& Charlet, G. (2002). Chitin fractionation and characterization in N,N-dimethylacetamide/lithium chloride solvent system. Carbohydrate Polymers, 50(4), 363-370.
Prasad, K., Murakami, M., Kaneko, Y., Takada, A., Nakamura, Y., \& Kadokawa, J. (2009). Weak gel of chitin with ionic liquid, 1-allyl-3-methylimidazolium bromide. Intermational Journal of Biological Macromolecules, 45(3), 221-225.

Qin, Y., Lu, X., Sun, N., \& Rogers, R. D. (2010). Dissolution or extraction of crustacean shells using ionic liquids to obtain high molecular weight purified chitin and direct production of chitin films and fibers. Green Chemistry, 12(6), 968-971.

Rosatella, A. A., Branco, L. C., \& Afonso, C. A. M. (2009). Studies on dissolution of carbohydrates in ionic liquids and extraction from aqueous phase. Green Chemistry, 11(9), 1406-1413.

Seddon, K. R., Stark, A., \& Torres, M.-J. (2007). Influence of chloride, water, and organic solvents on the physical properties of ionic liquids. Pure and Applied Chemistry, 72(12), 2275-2287.

Shamshina, J. L., \& Berton, P. (2020). Use of ionic liquids in chitin biorefinery: A systematic review. Frontiers in Bioengineering and Biotechnology, 8(11), 1-14.

Silva, S. S., Mano, J. F., \& Reis, R. L. (2017). Ionic liquids in the processing and chemical modification of chitin and chitosan for biomedical applications. Green Chemistry, 19(5), 1208-1220.

Skorik, Y. A., Pestov, A. V., \& Yatluk, Y. G. (2010). Evaluation of various chitin-glucan derivatives from Aspergillus niger as transition metal adsorbents. Bioresource Technology, 101(6), 1769-1775.

Stolte, S., Bottin-weber, U., Matzke, M., Stock, F., Thiele, K., Uerdingen, M., .. Ranke, J. (2006). Anion effects on the cytotoxicity of ionic liquids. Green Chemistry, 8 , $621-629$.

Swatloski, R. P., Spear, S. K., Holbrey, J. D., \& Rogers, R. D. (2002). Dissolution of cellulose with ionic liquids. Journal of the American Chemical Society, 124, 4974

Synytsya, A., \& Novak, M. (2014). Structural analysis of glucans. Annals of Translational Medicine, 2(2), 17

Taheri, N., Abdolmaleki, A., \& Fashandi, H. (2018). Pyridinium-based ionic liquid/water mixture intended for efficient dissolution of cellulose, chitosan and chitin: The pivotal contribution of water. Carbohydrate Polymers, 195, 413-419.

Tang, X., Zuo, M., Li, Z., Liu, H., Xiong, C., Zeng, X., ... Lin, L. (2017). Green processing of lignocellulosic biomass and its derivatives in deep eutectic solvents. ChemSusChem, 10(13), 2696-2706.

Tomé, L. C., Silva, N. H. C. S., Soares, H. R., Coroadinha, A. S., Sadocco, P., Marrucho, I. M., \& Freire, C. S. R. (2015). Bioactive transparent films based on polysaccharides and cholinium carboxylate ionic liquids. Green Chemistry, 17(8), 4291-4299.

Tran, C. D., Lacerda, S. H. D. P., \& Oliveira, D. (2003). Absorption of water by roomtemperature ionic liquids. Applied Spectroscopy, 57(2), 2-7.

Uto, T., Idenoue, S., Yamamoto, K., \& Kadokawa, J. I. (2018), Understanding dissolution process of chitin crystal in ionic liquids: Theoretical study. Journal of the Chemical Society Faraday Transactions, 20(31), 20669-20677.

Wang, H., Li, J., Zeng, X., Tang, X., Sun, Y., Lei, T., \& Lin, L. (2020). Extraction of cellulose nanocrystals using a recyclable deep eutectic solvent. Cellulose, 27(3), $1301-1314$

Wang, S., Peng, X., Zhong, L., Jing, S., Cao, X., Lu, F., \& Sun, R. (2015). Choline chloride/ urea as an effective plasticizer for production of cellulose films. Carbohydrate Polymers, 117, 133-139.

Wang, W. T., Zhu, J., Wang, X. L., Huang, Y., \& Wang, Y. Z. (2010). Dissolution behavio of chitin in ionic liquids. Journal of Macromolecular Science Part B- Physics, 49(3), 528-541.

Wu, R. L, Wang, X. L, L, F. Li, H. Z. \& Wang, Y. Z. (2009), Green composite films prepared from cellulose, starch and lignin in room-temperature ionic liquid. Bioresource Technology, 100(9), 2569-2574.

Wu, Y., Sasaki, T., Irie, S., \& Sakurai, K. (2008). A novel biomass-ionic liquid platform for the utilization of native chitin. Polymer, 49(9), 2321-2327.

Xu, J., McCarthy, S. P., Gross, R. A., \& Kaplan, D. L. (1996). Chitosan film acylation and effects on biodegradability. Macromolecules, 29(10), 3436-3440.

Yang, X., Qiao, C., Li, Y., \& Li, T. (2016). Dissolution and resourcfulization of biopolymers in ionic liquids. Reactive \& Functional Polymers, 100, 181-190.

Zdanowicz, M., Wilpiszewska, K., \& Spychaj, T. (2018). Deep eutectic solvents for polysaccharides processing. A review. Carbohydrate Polymers, 200, 361-380.

Zhang, C., Zhu, L., Wang, J., Wang, J., Zhou, T., Xu, Y., \& Cheng, C. (2017). The acute toxic effects of imidazolium-based ionic liquids with different alkyl-chain lengths and anions on zebrafish (Danio rerio). Ecotoxicology and Environmental Safety, 140 , 235-240.

Zhang, Y., Zhang, S., Lu, X., Zhou, Q., Fan, W., \& Zhang, X. P. (2009). Dual aminofunctionalised phosphonium ionic liquids for $\mathrm{CO}_{2}$ capture. Chemistry - $A$ European Journal, 15, 3003-3011.

Zhu, K., Shi, S., Cao, Y., Lu, A., Hu, J., \& Zhang, L. (2019). Robust chitin films with good biocompatibility and breathable properties. Carbohydrate Polymers, 212, 361-367. 